\title{
Is There Evidence of Gender Preference for Offspring in France? Examining the Predilections of Native Women and Immigrant Women from Asia and Africa
}

\author{
Sehar Ezdi, Sabrina Pastorelli
}

\begin{abstract}
This paper investigates gender preferences for offspring within the native French population and among immigrants from North Africa, Sub-Saharan Africa, Turkey and Vietnam-Cambodia-Laos in France by combining the Family and Housing Survey (2011) and the Trajectories and Origins Survey (2008). In so doing, it is the first paper to examine the persistence (or lack thereof) of gender preferences among immigrants in France. This allows the findings of the paper to serve as a tool for monitoring the immigrant integration process in the country. Using (multilevel) logistic regressions to examine transitions to second and third child births contingent upon gender of existing children and by migration status provides two main results. First, regarding evidence of gender preferences, the results show: mixed gender preferences and weak daughter preference among native French women when transitioning to the third parity; mixed gender preferences among secondgeneration Turkish immigrant women when transitioning to the third parity; and a daughter preference for second-generation North African, Sub-Saharan African and Vietnamese-Laos-Cambodian immigrant women when transitioning to the third parity. Second, for the immigrant sample, these preferences emerge in the face of declining fertility, across subsequent generations of immigrants, and on average as a deviation from their country of origin gender preferences. This not only points to the malleability of gender preferences for offspring but also lends credence to both the selection and adaptation hypotheses in explaining immigrant integration in France.
\end{abstract}

Keywords: Parental gender preferences $\cdot$ Immigrants $\cdot$ Migration status · Fertility decline $\cdot$ Transitions $\cdot$ Integration $\cdot$ Comparison 


\section{Introduction}

France has a long history of immigration dating back to the early 19th century, with immigrants arriving from other European countries (Pison 2019). More recent waves of immigrants, i.e. after the Second World War, included non-European immigrants from North Africa and later Sub-Saharan Africa and Asia (Pison 2019). Consequently, the immigrant population in France has formed gradually over the years, over successive waves of immigration (Pison 2019). In 2015, immigrants formed approximately 12.3 percent of the French population (Pison 2019). As of 2017, immigrants born in Africa and Turkey comprised 65.2 percent of the immigrant population (of which 29.5 percent were Algerian, Moroccan and Tunisian immigrants) and second-generation immigrants comprised 48.1 percent of the immigrant population (of which 32.3 percent were second-generation Algerian, Moroccan and Tunisian immigrants) in France (INED 2020).

The diversity in terms of country of origin of immigrants creates heterogeneity across first-generation immigrants in different communities on social and economic fronts (Algan/Bisin/Verdier 2012). First-generation immigrants may also display significant gaps vis-à-vis natives in terms of age at first marriage, education, age gap between spouses and fertility rates (Algan/Bisin/Verdier 2012). This is especially true for non-European immigrants from more recent waves of immigration who come from high fertility countries with a strong emphasis on traditional family values, parent-child ties and religion (Pailhé 2017). Nevertheless, research has shown a rapid integration process between first-generation and second-generation immigrants on almost all dimensions and for almost all groups of origin (Algan/ Bisin/Verdier 2012).

Academic literature has analysed various facets of the immigrant integration processes in France for both first-generation (e.g. Toulemon 2004) and secondgeneration (e.g. Pailhé 2017; Dupray/Pailhé 2018) immigrants in order to provide a quantitative assessment of the cultural integration path (Algan/Landais/Senik 2012). Nevertheless, one facet with the potential to provide crucial information on integration processes in France has largely been neglected to date, namely the possible existence of gender preferences among immigrants in France.

Given the persistence of gender preferences in North Africa (e.g. Arnold 1997), Turkey (e.g. Altindag 2016), Southeast Asia and possibly matrilineal and patrilineal societies of Sub-Saharan Africa (e.g. Rossi/Rouanet 2015), an examination of their existence among immigrants from these countries in France and a comparison of these preferences with those of the native French population is important for two reasons. First, gender preferences for offspring develop at the nexus of strong institutional, cultural and economic values. A change in gender preferences reflects a fundamental alteration in these values based on the futility of formerly held gender preferences in favour of new preferences. A change in gender preferences to match those of the host population thereby reflects the development of a value system similar to that of the native population, reflecting simultaneous integration on multiple fronts. Second, the relationship between fertility decline and gender preferences cannot be ignored. As fertility declines, the expression of gender 
preferences in a population group increases as women have fewer birth parities within which to achieve the desired gender constellation of their offspring (Guilmoto 2009). In France, the fertility of second-generation immigrants of various immigrant groups that exhibit gender preferences in their country of origin (e.g. North African, Sub-Saharan African, Southeast Asian; Kulu et al. 2017; Pailhé 2017) has converged to the level of the native French population.

Therefore, in order to fully understand the immigrant integration process, especially with regard to fertility, an examination of gender preferences is imperative to reveal how immigrants reconcile this lower fertility with the desired gender preferences for their offspring.

To this end, our paper combines data from the Trajectories and Origins Survey (2008) and the Family and Housing Survey (2011) to examine the existence of gender preference for offspring among native French women and immigrant women from North Africa, Sub-Saharan Africa, Turkey and Vietnam-Laos-Cambodia. In so doing, we seek to answer three research questions: (1) Do native French women exhibit gender preferences for offspring when transitioning to the second and/or third birth parity?; (2) Do immigrant women (in France) from North Africa ${ }^{1}$, Sub-Saharan Africa ${ }^{2}$, Turkey and Vietnam-Laos-Cambodia exhibit gender preferences for offspring when transitioning to the second and/or third birth parity, and how do these preferences (or lack thereof) compare with preferences in both the immigrant's country of origin and in France (from 1)?; and (3) How do gender preferences for offspring among immigrants (in France) from North Africa, Sub-Saharan Africa, Turkey and Vietnam-Laos-Cambodia change across subsequent generations of immigrants? In addressing these research questions, we make two main contributions to the literature available on this subject. First, we use relatively recent data to determine the extent to which gender preferences for offspring in France exist, among both native and immigrant women. Second, as far as we are aware, we are the first to examine the existence/persistence or development of gender preferences among immigrant communities in France, and thereby to use these preferences (or lack thereof) as a tool to navigate immigrant integration processes in the country.

Our paper is organised as follows: the next section provides the theoretical background alongside the research questions; Section 3 presents the data, analytical strategy and variables (dependent, explanatory and covariates); Sections 4 and 5 provide the results and discussion, respectively; Section 6 contains the conclusion.

Includes: Algeria, Morocco and Tunisia.

2 Includes: Senegal, Mauritania, Gambia, Guinea-Bissau, Guinea, Mali, Burkina Faso, Niger, Chad, Ivory Coast, Niger, Ghana, Togo, Benin, Nigeria, Cameroon, Central African Republic, Gabon, Congo, DR Congo, Equatorial Guinea. 


\section{Theoretical background}

\subsection{Universal gender preferences}

Gender preferences for offspring are a continuously evolving global phenomenon. In developing and developed countries, even when parents show a predilection for a specific gender, both sons and daughters are usually desired for distinct reasons (Arnold/Kuo 1984; Hank 2007). In developing countries, sons may be valued for economic reasons (e.g. old age support, inheritance rights), continuing the family name and performing burial rites for parents (Arnold/Kuo 1984). Daughters may be desired for companionship, non-financial care-giving and desirable personality traits (Arnold 1997). In developed countries, where economic motives are unlikely to be drivers of gender preferences, parents may perceive benefits derived from children in terms of expansion of self, affiliation, stimulation, accomplishment and social comparison to differ between sons and daughters (Hank 2007). Parents may exercise gender preferences by continuing to have children until the desired number of children of the preferred gender have been born or by using sex selection ultrasound technology to have an offspring of the preferred gender at the desired parity (Pison 2004).

Son preference is commonly observed across many countries in Asia, North Africa and the Caucasian region (Pison 2004; Guilmoto 2009; Duthé et al. 2012; Rossi/Rouanet 2015). Examples of countries where such preference is prominent include: China, India, Vietnam, Bangladesh, Pakistan, Turkey, Egypt, Morocco, Jordan, Armenia, Azerbaijan and Georgia (Arnold 1997; Pison 2004; Duthé et al. 2012; Guilmoto 2009; Fuse 2010). In some Asian countries, such as Cambodia, there is also a documented preference for daughters (Fuse 2010). In Sub-Saharan Africa, while no or mixed gender preferences prevail on average, weak son preference is dominant in patrilineal societies and daughter preference is common in the relatively few matrilineal societies (Rossi/Rouanet 2015).

Different permutations of gender preferences are also evident in Western countries. An analysis of 24 European countries shows that son preference is prominent in countries where gender equity is low and old age poverty is high (Mills/Begall 2010). Nevertheless, the majority of these countries show evidence of mixed gender preferences when transitioning to a third birth parity (Mills/Begall 2010). Parental preference for a gender mix of children has also been documented in Austria, Belgium, Hungary, Italy, Latvia, Slovenia, Spain, Switzerland, Australia, Canada, Denmark, United States and United Kingdom (Jacobsen et al. 1999; McDougall et al. 1999; Hank/Kohler 2000; Dahl et al. 2003; Gray/Evans 2005; Tian/ Morgan 2015).

Across all countries, modernisation resulting in a change in the societal gender system can be expected to equalise the value of sons and daughters in the long run, thereby producing indifference among couples with regard to the gender of their offspring (Pollard/Morgan 2002; Rossi/Rouanet 2015). A fleeting period of gender indifference emerged in the United States in the 1980s and 1990s, only to be reversed in favour of a gender mix in the 2000s (Pollard/Morgan 2002; Tian/ 
Morgan 2015). On the other hand, recent evidence from Western countries has shown that modernisation, increased levels of female labour force participation and the sharing of family responsibilities within the household are leading to the emergence of a daughter preference (Miranda et al. 2018). From the 1980s onwards, mothers in Denmark, Norway and Sweden exhibited daughter preference at the third parity (Andersson et al. 2006; Saarela/Finnäs 2014). From 2000 onwards, daughter preference became stronger in Sweden with mothers exhibiting it from the second parity onwards (Miranda et al. 2018). Similarly, historically changing gender preferences in East and West Germany evolved into a preference for gender mix of children alongside a weak preference for daugters in unified Germany in the 2000 s as a result of modernisation and policies of the welfare regime (Carol/Hank 2020; Ezdi/Baş 2020).

Gender preferences have been shown to be malleable in France as well. Retrospective fertility data from the 1962, 1975 and 1982 Family and Housing Surveys provides evidence for mixed gender preferences and weak son preference when transitioning to the third parity for births in the 1970s only (Desplanques 1987). This is accompanied by the later Fertility and Family Survey (1994), providing evidence of no gender preferences among offspring in France (Hank/Kohler 2000). We use two relatively recent surveys (Trajectories and Origins Survey 2008 and Family and Housing Survey 2011) to examine whether native French women exhibit gender preferences for offspring when transitioning to the second and/or third birth parity.

\subsection{Gender preferences and migration}

The effect of immigration on gender preferences provides a unique opportunity to investigate the extent of cultural integration of immigrants, as it indicates the extent to which immigrants abandon the cultural and social norms of their country of origin in favour of those of the host country. Several hypotheses discuss the manner in which migration may shape the fertility behaviour of immigrants. The socialisation hypothesis assumes that individuals develop their fertility preferences during their childhood. Hence, immigrants' fertility behaviour is similar to that of their country of origin (Kulu/Gonzalez-Ferrer 2014). The adaptation hypothesis, which hinges on re-socialisation, assumes that the current socio-cultural and economic environment of immigrants determines their fertility behaviour (Kulu/Gonzalez-Ferrer 2014). The selection hypothesis assumes that immigrants are a distinct group whose fertility preference and behaviour differ from their country of origin and resemble that of their host country (Kulu/Gonzalez Ferrer 2014). Transnationalism assumes that sustained connections to the country of origin enable immigrants to forge and sustain simultaneous multi-stranded social relations that link together their country of origin and host country (Afulani/Asunka 2015).

Some evidence points towards cultural adaptation of gender preferences in the fertility behaviour of immigrants. Tønnessen, Aalandslid, and Skjerpen (2013) find that Indian-born women in Norway gave birth to more girls than boys at higher orders in the 2006-2012 period compared with the 1969-2005 period, with this 
latter period witnessing a heavy concentration of male births at higher parities. Mussino, Miranda, and Ma (2018) find a positive effect of gender egalitarian values and universal welfare on Chinese, South Korean, and Indian immigrants' fertility preferences so that their sex ratios at birth (male/female) for the period 2000 to 2015 were lower than their significantly male-skewed sex ratios at birth for the period 1980 to 1999.

The majority of literature, however, shows that immigrant preferences continue to reflect the cultural norms in their country of origin. Asian immigrant populations originating from son-preferring countries (e.g. China, India, South Korea, and Pakistan), hosted in the United Kingdom, United States, Canada, Norway, Italy, Greece and Spain, have lower fertility than their counterparts in their country of origin and adopt son-preferring behaviour in a manner parallel to their country of origin (Dubuc/Coleman 2007; Abrevaya 2009; Gill/Mitra-Kahn 2009; Lillehagen/ Lyngstad 2018; Verrapoulu/Tsimbos 2010; Singh et al. 2010; Adamou et al. 2013; Almond et al. 2013; Gonzalez 2014; Ambrosetti et al. 2015). For Chinese, Indian, and South Korean immigrants, this implies the adoption of enabling technology in favour of sons at higher birth orders and a masculinised sex ratio at birth trajectory over time parallel to that of their home countries (Dubuc/Coleman 2007; Abrevaya 2009; Adamou et al. 2013; Almond et al. 2013). For Pakistani immigrants, this implies the adoption of the fertility-stopping rule until the final birth parity to ensure the birth of at least one son (Almond et al. 2013).

Immigrants in France arrive from countries that display different types of gender preferences: e.g. son preferences in North Africa, Turkey and Vietnam (Arnold 1997; Guilmoto 2009; Altindag 2016), an assortment of preferences (son/daughter/ mixed/none) in Sub-Saharan Africa (Rossi/Rouanet 2015); daughter preference in Cambodia (Fuse 2010). The manner in which these preferences are either retained or re-formulated may help obtain a multifaceted understanding of the integration process, especially as all immigrants do not solely come from son-preferring or daughter-preferring societies. To investigate this, we assess whether immigrant women (in France) from North Africa, Sub-Saharan Africa, Turkey and VietnamLaos-Cambodia exhibit gender preferences for offspring when transitioning to the second and/or third parity, and how these preferences (or lack thereof) compare with preferences in both the immigrant's country of origin and those of native women in France.

\subsection{Fertility and gender preferences in France}

With the exception of occasional spikes and dips, the total fertility rate (TFR) in France has remained roughly stable at approximately 1.84 per woman since 1975 (Toulemon et al. 2008; Pison 2020). France thus has one of the highest fertility rates in Europe (Volant et al. 2019). This is largely a consequence of the country's family policy which promotes fertility by reconciling pro-birth and family assistance objectives with work-family balance and female labour force participation (Toulemon et al. 2008). This has promoted a high level of fertility amongst working-age women, i.e. 30-40 years old (Toulemon et al. 2008). Hence, although the data shows that 
progression to first births has declined since 1975, progression to subsequent parities (i.e. second, third, fourth) has not changed, implying that a decline in first births does not lead to a decline in second births (Toulemon et al. 2008). A family of two to three children is the ideal completed family size in France, with most couples following the two child norm (Toulemon et al. 2008; Pailhé 2017). Until the early 1990s, gender preferences for offspring appeared to be flexible in France: having oscillated from no gender preferences, to mixed gender preferences accompanied by weak son preference, to no gender preferences (Desplanquess 1987; Hank) Kohler 2000).

Although the fertility behaviour of the children of immigrants in France displays a tendency to converge with French norms, with children of immigrants mostly adopting the norm of having two children (Dupray/Pailhé 2018), substantial heterogeneity in this convergence is observable amongst groups of immigrants (Penn/Lambert 2002; Algan/Landais/Senik 2012). This highlights the multifaceted nature of integration between first-generation and second-generation immigrants, which may be easier on some dimensions than others (Algan/Landais/Senik 2012). Women born in North Africa (Algerian, Moroccan and Tunisian) have the highest TFR of 3.5, whereas women born in Sub-Saharan Africa, Turkey and the rest of the world have an average of 3 children (Volant et al. 2019).

North African respondents in France have significantly higher fertility rates than those born in France or those who have acquired French citizenship (Penn/Lambert 2002). Nevertheless, women of North African descent (i.e. second generation) display the greatest convergence with French fertility patterns, especially with regard to first and second births (Pailhé 2017). A large proportion of these women have a first child later than native French women, and proceed to have a second and third child (Dupray/Pailhé 2018; Pailhé 2017). Turkish immigrants in France have significantly higher first birth rates than other population subgroups and maintain a very high third birth risk (Kulu et al. 2017). Second-generation Turkish immigrants enter motherhood earlier and have higher first, second and third birth risks than native French women, thereby indicating an adherence to their parents' fertility preferences (Pailhé 2017). Sub-Saharan African immigrants of the first generation have higher fertility than both the native French population and other immigrant subgroups in the country (Afulani/Asunka 2015). Second-generation Sub-Saharan African immigrants appear to adapt to the society of settlement, postpone first and second births, and hence display fertility patterns similar to those of native French women (Afulani/Asunka 2015; Pailhé 2017). Second-generation Southeast Asian immigrant women in France deviate from the fertility patterns of their parents and converge with the French norm (Pailhé 2017). They postpone childbearing and have their first child significantly later than native French women but show no significant difference with regard to the timing of second births (Pailhé 2017). Hence, with the exception of second-generation Turkish immigrant women who continue to adhere to their parents' fertility preferences, second-generation descendants of North African, Sub-Saharan and Southeast Asian origin have a strong tendency to align with French standards. 
Given the steep convergence in fertility behaviour amongst second-generation immigrants and the heterogeneity in these transitions between different generations of immigrants, we seek to analyse how gender preferences for offspring among immigrants (in France) from North Africa, Sub-Saharan Africa, Turkey and VietnamLaos-Cambodia change across subsequent generations of immigrants.

\section{$3 \quad$ Methodology}

\subsection{Data}

We combine data from two nationally representative surveys in France: the Family and Housing Survey (2011); and the Trajectories and Origins Survey (2008). The Family and Housing Survey (2011) is a joint collaboration among the National Institute of Statistics and Economic Studies (INSEE), the National Institute for Demographic Studies (INED), the Department for Research Evaluation and Statistics (DREES) and the National Family Allowance Fund (CNAF, CASD n.d.). It is based on a sample of 360,000 individuals aged 18 years or older residing in 400,000 private dwellings across metropolitan France. Key issues addressed by the survey include fertility, partnership information, family structuring and restructuring, child care, information on parents and grandchildren, geographical distribution of the family, multiple residences and civil solidarity pacts (INSEE 2020). Given these domains it allows fertility analysis to be performed by generation, socio-demographic origin or geographic origin, and is useful for the detailed investigation of distinct family situations and quantitative analysis of minority situations that are often inaccessible in large surveys (CASD n.d.). The 2011 survey is the most recent and most evolved wave of the Family and Housing Survey in not only incorporating family history, male respondents and regional respondents, but also providing detailed descriptions of current marital status and family situations (INSEE 2020).

The Trajectories and Origins Survey (2008-2009) is a joint collaboration between INED and INSEE conducted with the aim of identifying the impact of origin on living conditions and social trajectories (INED 2020). Based on a sample of 22,000 people residing in metropolitan France, it collates relevant data on sociodemographic characteristics such as age, gender, level of education, generation, social environment and neighbourhood of residence (INED 2020). Given its focus on highlighting the diversity of the French population, it places special emphasis on sub-populations who, due to their origin or appearance, may encounter obstacles in their life trajectories, i.e. immigrants, descendants of immigrants, individuals from French overseas territories, descendants of the latter (INED 2020). The 2008-2009 survey is the first and, at present, only available wave of the Trajectories and Origins Survey (INSEE 2020).

The two surveys are combined to not only maximise the sample size, especially for immigrant groups that form a relatively smaller proportion of the migrant population in France (e.g. Southeast Asian immigrants), but also to add a wider range of recent childbirth years for the examination of gender preferences (i.e. by 


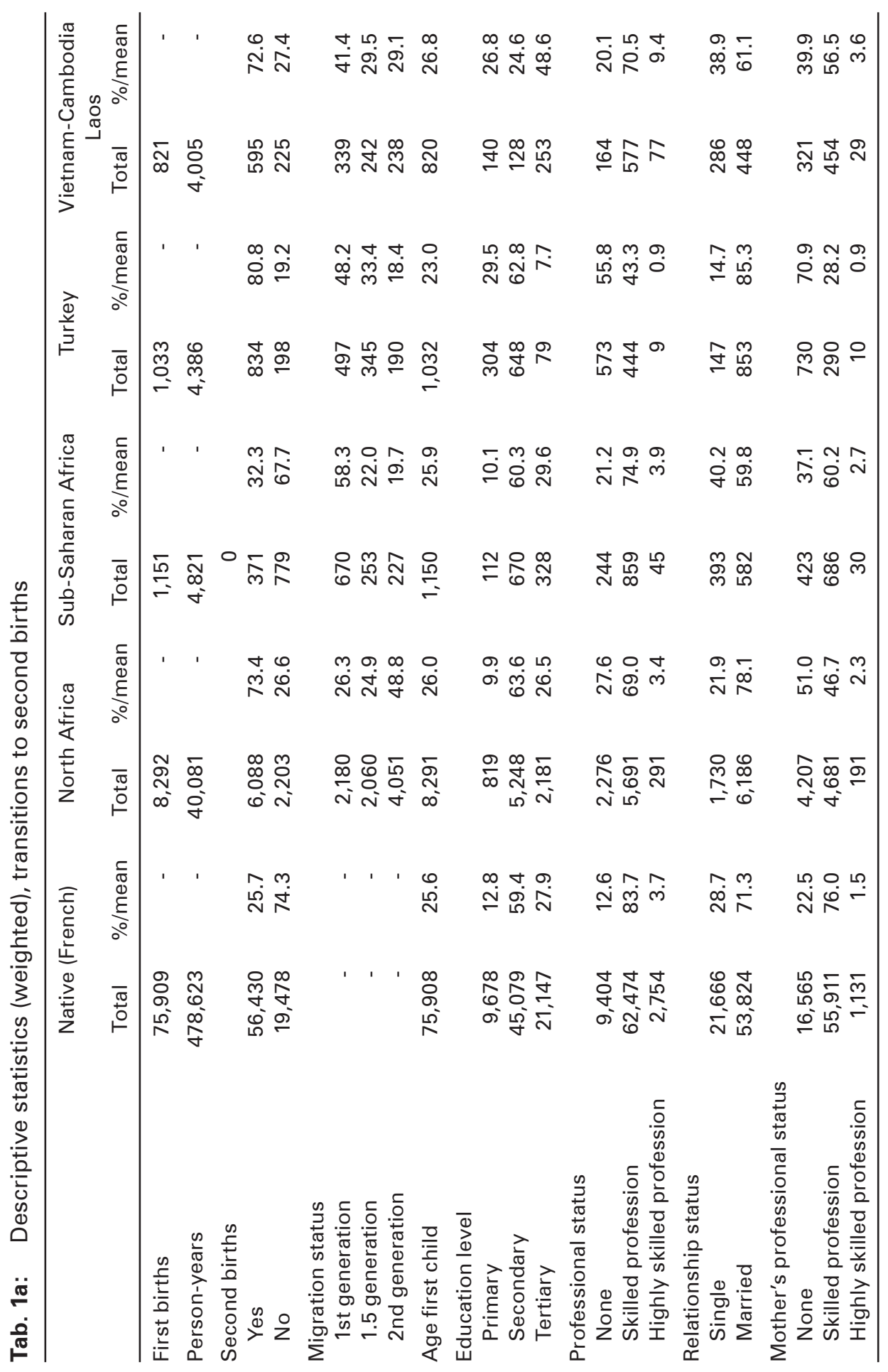




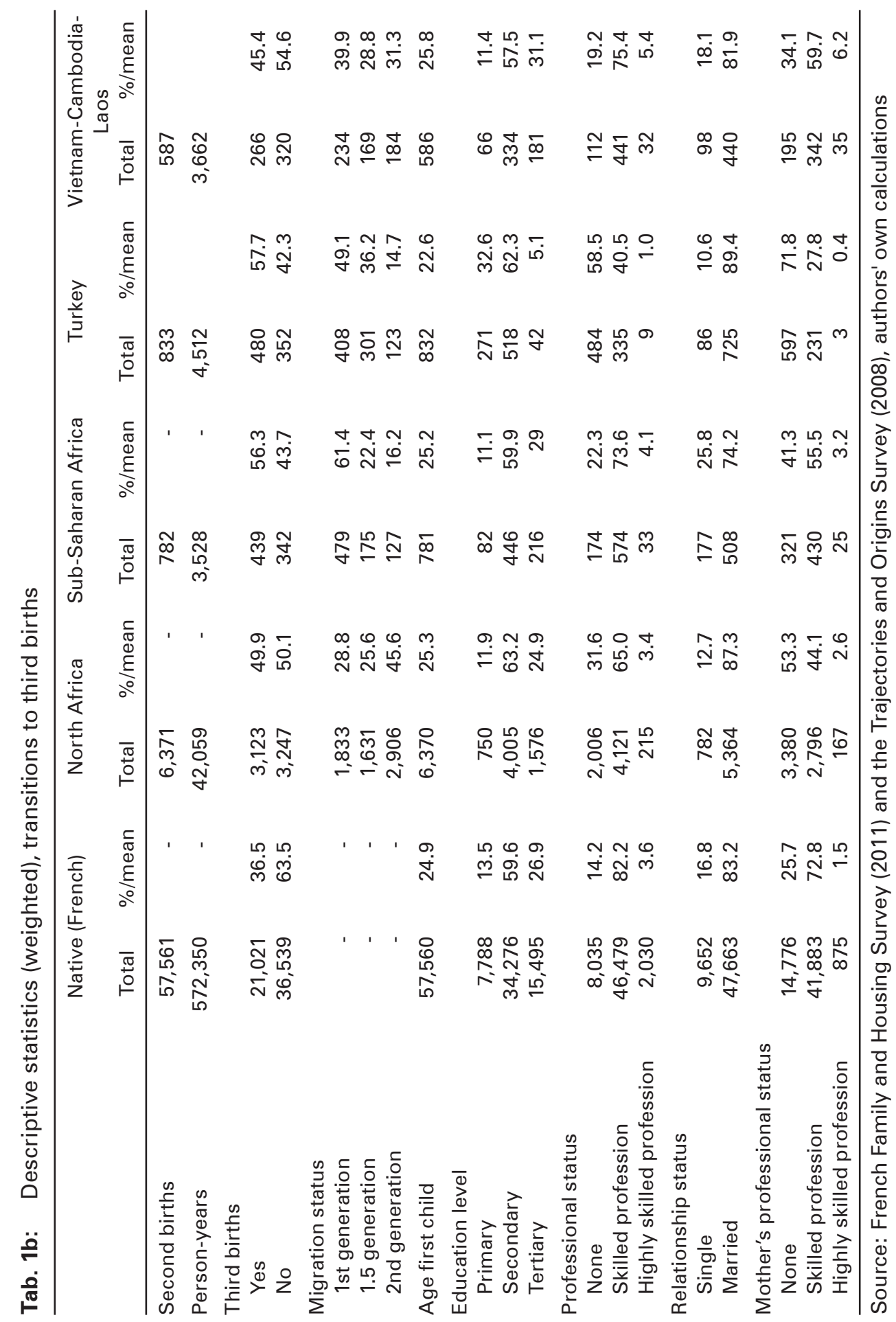


the incorporation of the 2011 Survey). Appropriate weights are used in all analyses to ensure that the sample is nationally representative.

The subjects of the study are women aged 16 to 45 who have given birth to at least one child. These respondents are either native French women or immigrant women of the first generation, 1.5 generation or second generation from North Africa, Sub-Saharan Africa, Turkey and Vietnam-Laos-Cambodia. Data from the survey is used to construct fertility histories for first, second, and third childbirths for the respondents of interest. Only women who had their first child after migration are included in the sample.

Respondents with multiple births and fostered and adopted children up to the third parity are excluded from the sample, as are respondents who present missing information on their own date of birth, date of birth of children at the first, second, or third parity, and migration status. Tables $1 \mathrm{a}$ and $1 \mathrm{~b}$ provide an overview of the final sample to be analysed.

\subsection{Methods}

We conduct the analysis for each group of origin separately: for the native (French) population we use discrete time logistic regression and for each separate immigrant group (North African, Sub-Saharan African, Turkish and Vietnamese-LaosCambodian), we use multilevel discrete time logistic regression. We first examine transitions to second and third births for native and immigrant women contingent upon the gender of the first child and of the first two children, respectively, while incorporating the role of migration status for each immigrant group. Subsequently, we subdivide the sample of each immigrant group by gender of the first (boy/girl) and first two (boy/girl/mix) child(ren) and investigate transitions to second and third births respectively while accounting for migration status.

Discrete time hazard $h_{i j}$ is the conditional probability that a randomly selected individual $i$ will experience the target event in time period $j$ given that he or she survived through all prior time periods and did not experience the event prior to $j$ (Singer/Willet 1993):

$$
\mathrm{h}_{\mathrm{ij}}=\operatorname{Pr}\left\{\mathrm{T}_{\mathrm{i}}=\mathrm{j} \mid \mathrm{T}_{\mathrm{i}} \geq \mathrm{j}, \mathrm{Z}_{1 \mathrm{ij}}=\mathrm{z}_{1 \mathrm{ij}}, \mathrm{Z}_{2 \mathrm{ij}}=\mathrm{z}_{2 \mathrm{ij}}, \ldots, \mathrm{Z}_{\mathrm{Pij}}=\mathrm{z}_{\mathrm{Pij}}\right\}
$$

Since $h_{i j}$ are probabilities, they can be transformed to have logistic dependence on the predictors and the time periods (Singer/Willet 1993):

$$
\operatorname{logit}_{e}\left(h_{i j}\right)=\left(\alpha_{1} D_{1 i j}+\alpha_{2} D_{2 i j}+\ldots+\alpha_{J} D_{J i j}\right)+\left(\beta_{1} Z_{1 i j}+\beta_{2} Z_{2 i j}+\ldots+\beta_{P} Z_{P i j}\right)
$$

This specification clarifies that the conditional log odds that the event will occur in each time period $j$ (given that it did not occur before) is a linear function of the constant term, $\alpha_{j}$, specific to period $j$ and of the values of predictors period $j$ multiplied by the appropriate slope parameter. Multilevel models are fitted to immigrant subgroups to account for the hierarchical structure of the data within each 
group (i.e. individuals classified by migration status: first generation, 1.5 generation, second generation). The methods employed in this paper, i.e. (multilevel) logistic regression models and contingency on gender of existing children, are commonly used by researchers investigating fertility transitions (e.g. Pailhé 2017; Kulu et al. 2017; Dupray/Pailhé 2018) and gender preferences (e.g. Miranda et al. 2018; Ezdi/ Baş 2020) in both local and immigrant populations.

\subsection{Variables}

The dependent variable of interest is the probability of second or third childbirth for each origin group. To construct data for this variable, the fertility trajectories of the sample are followed until the occurrence of the second and subsequently third childbirth in the case of event occurrence. Alternatively, in the case of event nonoccurrence, the sample of interest is followed until the respondent turns 45 or until the date of last interview (right censoring).

The analysis incorporates two explanatory variables: gender of existing children and migration status. Gender of existing children is a categorical variable assuming the status of boy/girl when transitioning to the second parity and boy-boy/gender mix/girl-girl when transitioning to the third parity. This variable is included to depict how transition to subsequent parities is affected by different gender combinations of existing children, and thereby to indicate which gender constellation is most desired at each parity.

Migration status has four categories: non-immigrant, first-generation immigrant, 1.5-generation immigrant, and second-generation immigrant. The non-immigrant category comprises both French-born individuals with two French-born parents and non-French-born individuals with two French-born parents who moved to France before the age of 15 . The non-immigrant category is distinct from all other categories as it refers to the native French population. First-generation immigrant refers to foreign-born individuals with foreign-born parents, and who migrated to France at age 15 or later. 1.5-generation immigrant refers to individuals with foreignborn parents, and who migrated to France before the age of 15. Second-generation immigrant refers to French-born individuals with one or two foreign-born parents. Different levels of gradation in migration status allow us to account for the effect of integration on son preference.

We incorporate the same six covariates for transitions to second and third births for all population groups in both sets of analyses. These include: age at the time of first birth, age squared at the time of first birth, education, relationship status, professional status, and mother's professional status in France. Education is recorded as the highest educational attainment of the respondent at the time of the survey and is recoded as primary, secondary or tertiary level of education. Relationship status is recorded as the respondent being either single or married at the time of first birth when considering transitions to second births, and at the time of second births when considering transitions to third births. Professional status is recorded as the respondent falling into the category of no occupation, skilled occupation or highly skilled occupation. Mother's professional status is recorded as 
the respondent's mother having fallen under the category of no occupation, skilled occupation or highly skilled occupation at the time the respondent was 15 years of age. These covariates were incorporated due to their relevance as determinants of fertility and gender preferences for offspring, as identified by previous literature (e.g. Rossi/Rouanet 2015; Jiang et al. 2016; Pailhé 2017; Ezdi/Baş 2020).

\section{Results}

\subsection{Transition to second births}

Table 2 shows the logistic regression results as average marginal effects for transition to second births for the native population and different immigrant groups in France. The gender of the first child significantly affects the probability of transition for North African immigrants only: women who have a daughter as a first child are significantly more likely to transition to a second birth than those who have a son. Migration status significantly affects North African and Turkish immigrants. For North Africa, compared to first-generation immigrants, both 1.5-generation and second-generation immigrants have a significantly lower probability of transitioning to the second parity. Among Turkish immigrants, this applies to the latter group only.

Tab. 2: Results of transitions from first to second births, presented as average marginal effects of logistic regressions, run separately for each population group

\begin{tabular}{|c|c|c|c|c|c|}
\hline & $\begin{array}{c}\text { Native } \\
\text { (French) }\end{array}$ & $\begin{array}{l}\text { North } \\
\text { Africa }\end{array}$ & $\begin{array}{l}\text { Sub- } \\
\text { Saharan } \\
\text { Africa }\end{array}$ & Turkey & $\begin{array}{c}\text { Vietnam- } \\
\text { Cambodia- } \\
\text { Laos }\end{array}$ \\
\hline \multicolumn{6}{|c|}{ Gender of first child (Ref.: male) } \\
\hline Female & $\begin{array}{r}.005 \\
(.005)\end{array}$ & $\begin{array}{l}.027^{* *} \\
(.009)\end{array}$ & $\begin{array}{l}-.004 \\
(.015)\end{array}$ & $\begin{array}{r}.014 \\
(.014)\end{array}$ & $\begin{array}{l}-.001 \\
(.015)\end{array}$ \\
\hline \multicolumn{6}{|c|}{ Migration status (Ref.: First-generation) } \\
\hline 1.5-generation & $\begin{array}{l}- \\
-\end{array}$ & $\begin{array}{l}-.030 * * \\
(.010)\end{array}$ & $\begin{array}{l}-.003 \\
(.018)\end{array}$ & $\begin{array}{l}-.009 \\
(.017)\end{array}$ & $\begin{array}{r}.026 \\
(.020)\end{array}$ \\
\hline Second-generation & $\begin{array}{l}- \\
-\end{array}$ & $\begin{array}{l}-.020^{*} \\
(.009)\end{array}$ & $\begin{array}{r}-.023 \\
(.017)\end{array}$ & $\begin{array}{l}-.047^{*} \\
(.019)\end{array}$ & $\begin{array}{r}.009 \\
(.018)\end{array}$ \\
\hline Person years & 478,623 & 40,081 & 4,821 & 4,386 & 4,005 \\
\hline Sample size & 75,909 & 8,292 & 1,151 & 1,033 & 821 \\
\hline
\end{tabular}

Note: Controls: Age at first birth; Age at first birth square; Education; Professional status; Relationship status; Professional status of respondent's mother.

Significance levels: ${ }^{*}=\mathrm{p}$-value $<0.05 ;{ }^{* *}=\mathrm{p}$-value $<0.01 ;{ }^{* * *}=\mathrm{p}$-value $<0.001$; Standard errors in parentheses

Source: French Family and Housing Survey (2011) and the Trajectories and Origins Survey (2008), authors' own calculations 
Table 3 divides the results for immigrant population groups by the gender of the first child to separately assess the effect of migration status on the probability of having a second child. The results show that migration status significantly alters gender preferences for North African immigrant women only. If the first child is a boy, the 1.5-generation of immigrants has a significantly lower probability of transitioning to a second birth compared to first-generation immigrants. If the first child is a girl, second-generation immigrants have a significantly lower probability of having another child than first-generation immigrants.

\subsection{Transition to third births}

Table 4 provides the logistic regression results as average marginal effects for transition to third births for all population groups in France. The gender of existing children significantly affects the transition probability of the native French population only: women who achieve a gender mix of children at the first two parities are significantly less likely to transition to a third birth compared to women who have two sons. Although statistically non-significant, our results also show that native French women who have daughters at the first two parities have a lower probability of transitioning to a third birth. Migration status significantly affects transition probability for all immigrant groups. North African and Sub-Saharan African women of the 1.5 and second generation have a significantly lower probability of transitioning to a third birth compared to their first-generation counterparts. This only holds true for secondgeneration women from Turkey and Vietnam-Laos-Cambodia.

Following the logic of Table 3, Table 5 divides the results for each population group by gender of the first two children in order to separately assess the effect of migration status on the probability of having a third child. This yields significant results for all immigrant groups. AmongstNorth African women with a gender mix and daughters only at the first two parities, the probability of transitioning to a third birth is significantly lower for 1.5-generation and second-generation women compared with first-generation women. For North African women with two sons, this applies only to the 1.5-generation. For Sub-Saharan African women, only secondgeneration immigrant women with daughters only at the first two parities have a significantly lower probability of transitioning to a third parity than first-generation women. For Turkish women, second-generation immigrant women who have achieved a gender mix of children at the first two parities have a significantly lower probability of transitioning to a third parity than first-generation women. Among women from Vietnam-Cambodia-Laos, immigrant women of the second generation who achieve a gender mix of children or daughters only at the first two parities have a significantly lower probability of transitioning to a third birth than women of the first generation. This is accompanied by a higher, albeit non-significant, likelihood of transitioning to a third birth for second-generation vs. first-generation immigrant women from Vietnam-Cambodia-Laos in the event of sons only at the first two parities. 
Is There Evidence of Gender Preference for Offspring in France? 317

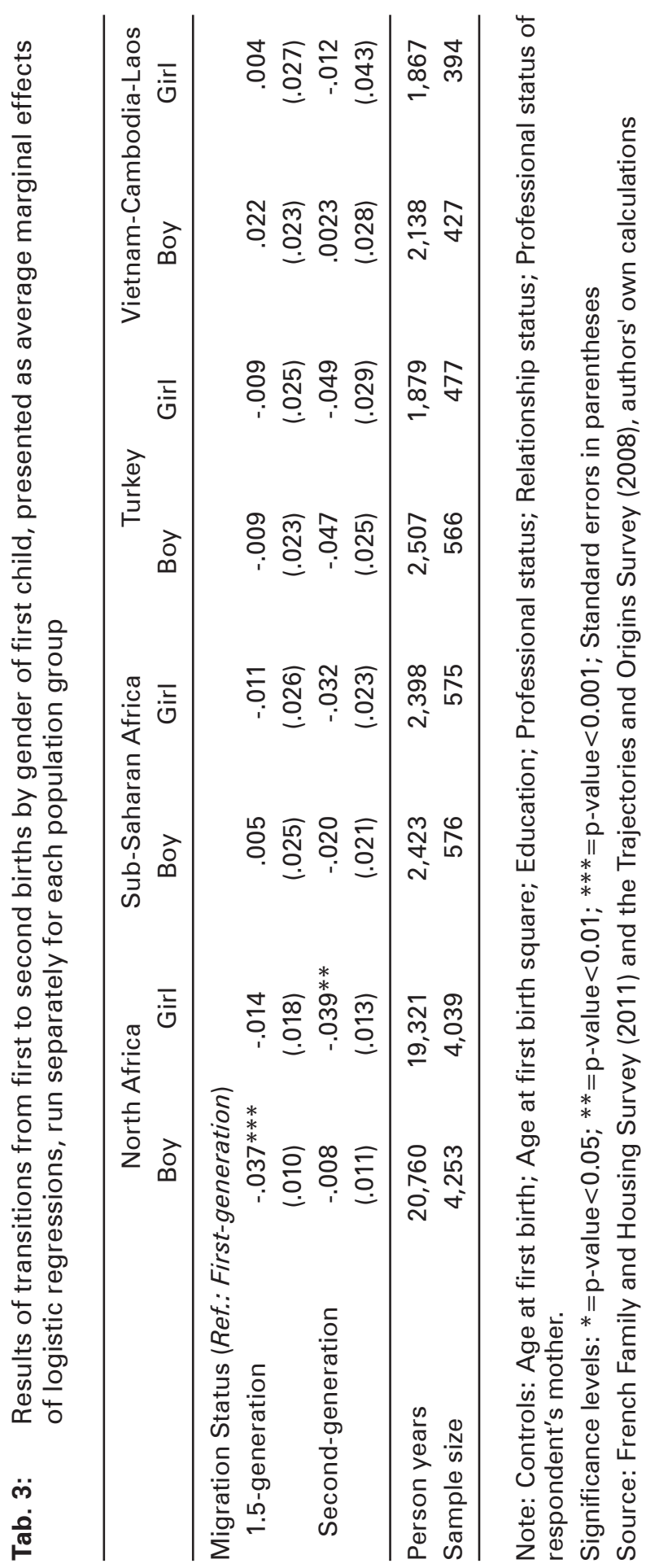


Tab. 4: Results of transitions from second to third births, presented as average marginal effects of logistic regressions, run separately for each population group

\begin{tabular}{|c|c|c|c|c|c|}
\hline & $\begin{array}{l}\text { Native } \\
\text { (French) }\end{array}$ & North Africa & $\begin{array}{c}\text { Sub- } \\
\text { Saharan } \\
\text { Africa }\end{array}$ & Turkey & $\begin{array}{c}\text { Vietnam- } \\
\text { Cambodia- } \\
\text { Laos }\end{array}$ \\
\hline \multicolumn{6}{|c|}{ Gender of first two children (Ref:: Boy-boy) } \\
\hline Gender mix & $\begin{array}{l}-.015^{* * *} \\
(.003)\end{array}$ & $\begin{array}{r}-.006 \\
(.005)\end{array}$ & $\begin{array}{r}-.017 \\
(.016)\end{array}$ & $\begin{array}{l}-.003 \\
(.012)\end{array}$ & $\begin{array}{l}-.002 \\
(.015)\end{array}$ \\
\hline Girl-girl & $\begin{array}{r}-.000 \\
(.004)\end{array}$ & $\begin{array}{r}.009 \\
(.007)\end{array}$ & $\begin{array}{l}-.003 \\
(.025)\end{array}$ & $\begin{array}{r}.017 \\
(.016)\end{array}$ & $\begin{array}{r}.023 \\
(.018)\end{array}$ \\
\hline \multicolumn{6}{|c|}{ Migration status (Ref.: First-generation) } \\
\hline 1.5-generation & - & $\begin{array}{l}-.027^{* * *} \\
(.004)\end{array}$ & $\begin{array}{l}-.036^{*} \\
(.016)\end{array}$ & $\begin{array}{r}.006 \\
(.012)\end{array}$ & $\begin{array}{l}-.005 \\
(.013)\end{array}$ \\
\hline Second-generation & - & $\begin{array}{l}-.019 * * \\
(.006)\end{array}$ & $\begin{array}{l}-.039 * \\
(.017)\end{array}$ & $\begin{array}{l}-.050 * * * \\
(.013)\end{array}$ & $\begin{array}{l}-.033^{*} \\
(.015)\end{array}$ \\
\hline Person years & 572,350 & 42,058 & 3,529 & 4,512 & 3,662 \\
\hline Sample size & 57,561 & 6,371 & 782 & 833 & 452 \\
\hline
\end{tabular}

Controls: Age at first birth; Age at first birth square; Education; Professional status; Relationship status; Professional status of respondent's mother.

Significance levels: ${ }^{*}=p$-value $<0.05 ;{ }^{* *}=p$-value $<0.01 ;{ }^{* * *}=p$-value $<0.001$; Standard errors in parentheses

Source: French Family and Housing Survey (2011) and the Trajectories and Origins Survey (2008), authors' own calculations

\section{Discussion}

Using data from the Family and Housing Survey (2011) and the Trajectories and Origins Survey (2008), we examined gender preferences for offspring within the native French population and among North African, Turkish, Sub-Saharan African and Vietnamese-Laos-Cambodian immigrants in France. Our analyses highlight how the gender of existing children and migration status (in the case of immigrants) may be reflected in both parity progression and underlying gender preferences. This investigation provides several interesting results. First, for all our immigrant groups, we confirm declining fertility rates across subsequent generations of immigrants.

For North Africa and Sub-Saharan Africa, 1.5-generation and second-generation immigrants have a significantly lower probability of transitioning to second and third births and third births only, respectively, vis-à- first-generation immigrants. For Turkey and Vietnam-Cambodia-Laos, second-generation immigrants have a significantly lower probability of transitioning to second and third births, and to third births only, respectively, vis-à-vis first-generation immigrants. On average, these findings are consistent with existing research which depicts declining fertility 
Is There Evidence of Gender Preference for Offspring in France? $\quad 319$

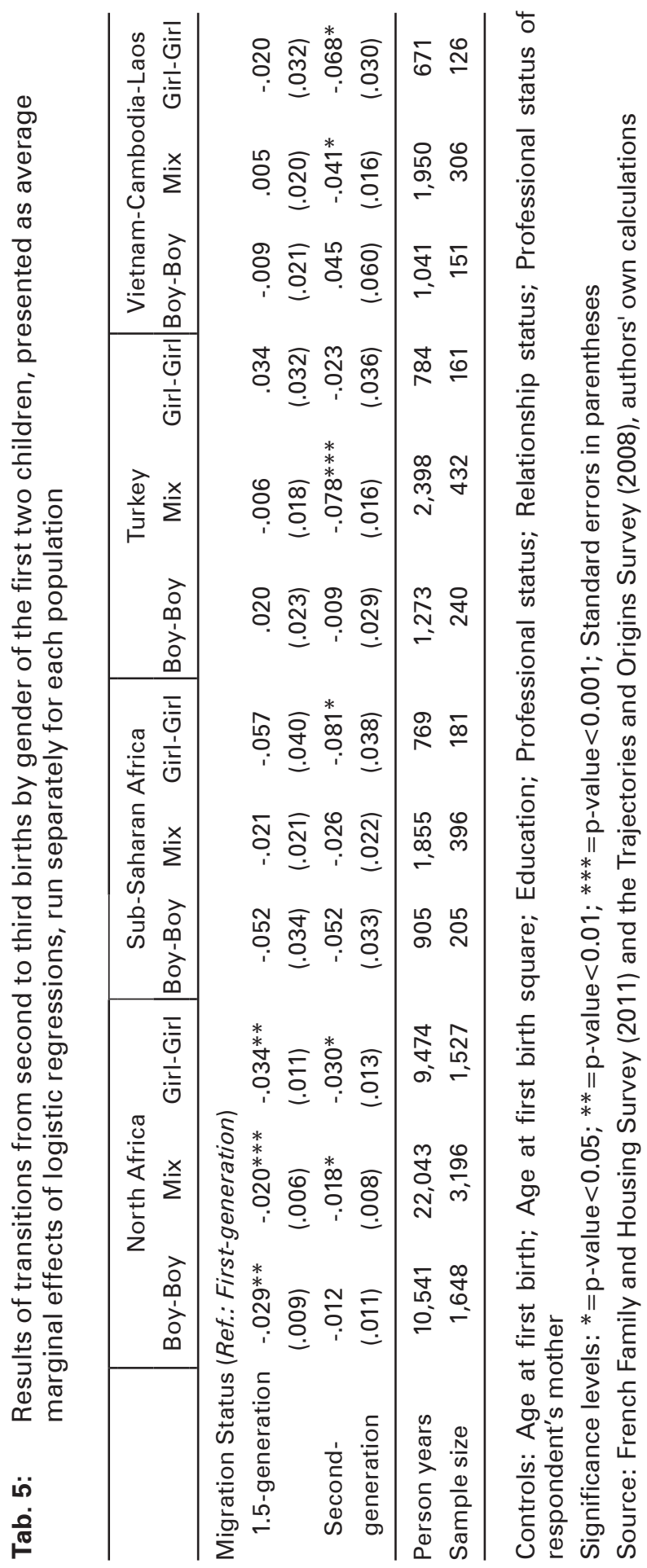


rates for second-generation immigrants in France and in Europe (Kulu et al. 2017; Pailhé 2017; Dupray/Pailhé 2018).

Second, our results reveal whether the gender of existing children affects transition to second and third births for native French women and immigrant women in France. For native French women, while we find no significant effect of the gender of the first child when transitioning to the second parity, we find a significant preference for a gender mix of children when transitioning to the third parity. Furthermore, we find a non-significant daughter preference when transitioning to the third parity. Our results signalling a preference for a gender mix of children are consistent with those of Desplanques (1987) who, using the 1962, 1975 and 1982 Family and Housing Surveys, also finds a preference for a gender mix of children when transitioning to the third parity in the 1970s in France. At the same time, our results for the non-significant daughter preference are also at odds with Desplanques (1987) who, in addition to finding a gender mix for offspring, finds evidence of weak son preference in the 1970s when transitioning to the third parity. Our results are also somewhat different from those of Hank and Kohler (2000) who find no gender preferences for offspring in France based on the Fertility and Family Survey (1994). These discrepancies can be reconciled by noting that the different studies (i.e. Desplanques 1987; Hank/Kohler 2000 and the current analysis) use data that examine gender preferences among native women for different birth cohorts of women in France. The different gender preferences for offspring noted amongst these studies thereby depict the changing nature of these preferences in France: from no gender preferences, to mixed-gender preferences accompanied by a weak son preference, to no gender preferences, to mixed-gender preferences accompanied by a weak (non-significant) daughter preference. Such an evolution in gender preferences has been noted in other European countries as well. For example, in Germany, mixed-gender preferences were previously only observed in the East (Hank/Kohler 2003). However, over the past two decades they have also become evident in the West and hence unified Germany, alongside a weak daughter preference (Carol/Hank 2020; Ezdi/Baş 2020). In Sweden, daughter preference has strengthened in the new millennium with mothers fertility transitions being conditional upon having a daughter at one parity earlier, i.e. second rather than third (Miranda et al. 2018). The adaptability of gender prefrences and non-significant daughter prefrence in France suggest that modernisation, change in the societal gender system, female labour force participation and work-family reconciliation policies may lead to the emergence of a strong daughter preference at the third parity among younger/future cohorts of French women (Pollard/Morgan 2002; Miranda et al. 2018).

For immigrant women in France, the gender of existing children only affects the transition probability of North African immigrant women. Women who have a daughter as a first child have a significantly higher likelihood of transitioning to a second birth than those who have a son. However, when considering transitions to the third parity, the gender sequence of existing children has no significant bearing on the probability of transition. This can possibly be explained by the polarisation of fertility rates between immigrants of the first-generation and subsequent 
(in particular second) generation, with the former displaying the highest fertility levels amongst all population subgroups in France and the latter exhibiting native level fertility rates (Penn/Lambert 2002; Volant et al. 2019). Furthermore, among second-generation North African immigrants, the rates of transition to different parities differ, with transitions to second parity being the same as the native level and transitions to third parity exceeding the native level (Kulu et al. 2017). For second-generation North African immigrants, this confirms an adaptation to the strong French two child norm regarding the timing of transition to the second parity, but the maintenance of the parents' family-oriented values when considering transitions to third parities (Pailhé 2017). As a result, we expect the son preference observed at the second parity among North African immigrants in France to be due to a contraction in fertility when transitioning to the second parity.

Third, our results allow us to disaggregate and compare transitions for immigrants simultaneously by gender of existing children and migration status. We find significant effects for all immigrant groups. For North African immigrants, we confirm that regardless of the gender of the first child, each subsequent generation (1.5 and second) has a lower likelihood of transitioning to the next parity. When transitioning to the second parity, these results are significant for 1.5-generation immigrants who have a son as a first child and second-generation immigrants who have a daughter as a first child. This may be interpreted as declining son preference across subsequent generations of North African immigrants when transitioning to the second parity. When transitioning to the third parity, these results are only nonsignificant for second-generation immigrants who have two sons at the first two parities. This may be interpreted as the emergence of a weak daughter preference amongst second-generation North African immigrants when transitioning to the third parity. ${ }^{3}$ The decline in son preference and emergence of a weak daughter preference may be explained by a combination of the selection and adaptation hypotheses, especially given the convergence and non-convergence to native French levels in transition rates to the second and third parities respectively (Ku/u et al. 2017). North African immigrants in France are not part of a marginal, rural, pre-modern group but rather have above average educational levels and French language abilities (Penn/Lambert 2002). These attributes point to the selectivity of North African immigrants so that perhaps even in their country of origin, their gender preferences are malleable. Hence, it is likely that a welfare regime that is not only pro-birth but also promotes a work-family balance and women's employment (Toulemon et al. 2008) eventually creates an environment in which these preferences can emerge, despite the fertility constraints when transitioning to the second parity.

For Sub-Saharan African immigrants, we find that only women who have daughters at the first two parities have a significantly lower probability of transitioning to the third birth. These results depict the emergence of a daughter preference among Sub-Saharan African immigrants when transitioning to the third

3 For 1.5-generation immigrants, our results signal lower fertility vis-à-vis first-generation immigrants as the likelihood of transition is significantly lower for all gender combinations. 
parity. The emergence of gender preferences for offspring among Sub-Saharan African immigrant women is somewhat surprising, primarily because individual countries in Sub-Saharan Africa have either not shown any gender preferences for offspring or, when present, such preferences have been rather modest compared with those displayed by Asian countries. Sub-Saharan Africa consists of countries/societies displaying son preference, daughter preference, gender-mixed preferences and no gender preferences (Rossi/Rouanet 2015). As our sample does not disaggregate among these countries/societies, we did not expect any overall gender preferences to prevail. We especially did not expect the emergence of a daughter preference because research from Sweden, a country with a pro-fertility gender egalitarian welfare regime, has shown that African women display son preference when transitioning to third births (Mussino et al. 2019). Nevertheless, our results for Sub-Saharan Africa may be explicable by the adaptation hypothesis. Adaptation has already been shown to reduce fertility among second-generation Sub-Saharan African immigrants in France (Afulani/Asunka 2015). In the case of gender preferences for offspring, the factors that have led to the emergence of a gender mix in France may be the drivers of daughter preference in Sub-Saharan Africa by not only weakening son preference in patrilineal societies but also eliminating gender preferences in societies that desire a gender mix and that exhibit no gender preferences for offspring. In light of the findings for Sweden (Mussino et al. 2019), our results would suggest greater adaptation among Sub-Saharan African immigrants in France than in Sweden.

Among Turkish immigrants, we find that only second-generation women with a gender mix of children have a significantly lower likelihood of transition than first-generation Turkish immigrants. This is accompanied by lower non-significant transition probabilities to third parities among second generation immigrant women who have sons only or daughters compared with their first generation counterparts. These preferences are somewhat evident within the 1.5 generation as well: albeit non-significant, women with a gender mix of children have a lower probability of transitioning to the third parity and women with sons only or daughters only have a higher probability of transitioning to the third parity compared with their respective first generation counterparts. Although Turkish women in their country of origin display son preference when transitioning to the third parity (Altindag 2016) and Turkish immigrants in Sweden display son preference (Mussino et al. 2019), our result for the emergence of gender-mixed preferences among Turkish immigrants in France is entirely plausible. Research on the gender preferences of Turkish immigrants in Germany provides evidence of the changing nature of gender preferences across subsequent generations of immigrants and the emergence of a preference for a gender mix for children when transitioning to the third parity among second-generation Turkish immigrants (Carol/Hank 2020; Ezdi/Bas 2020). This may be explained by the following factors: either by immigrant selectivity; or by the joint effect of higher fertility among Turkish immigrant women in Europe visà-vis Turkish women in Turkey and the higher fertility of Turkish immigrant women (transition to second births) in France relative to other population groups (BaykaraKrumm/Milewski 2017; Pailhé 2017). The latter explanation provides women with 
fewer constraints in which to exercise their preferences and ensures a slower convergence with native French fertility levels, possibly allowing Turkish immigrant women ample time to simultaneously adjust their fertility and gender preferences.

For immigrants from Vietnam-Laos-Cambodia, migration status has no significant bearing on the probability of transitioning to second births. Relative to first-generation immigrants, second-generation immigrants with a gender mix of children and daughters at the first two parities have a significantly lower probability of transitioning to the third parity. This suggests a daughter preference among second-generation immigrants from these countries in France. We cannot conclusively assert whether this daughter preference signals an evolution of the gender preferences or migrant selectivity for Vietnam (where boy preference dominates), or the prevalence of country of origin norms for Cambodia (where girl preference dominates) as different gender preferences from different countries of origin were combined to form a single immigrant group. Mussino, Miranda and Ma (2018) face a similar problem when they test the gender preferences of Southeast Asian immigrants in Sweden from different origin countries (displaying different gender preferences) combined to show that immigrants originating from this region display neutral gender preferences. Nevertheless, we suspect that this daughter preference is at least partly driven by a deviation from country of origin gender norms as it is evident among second-generation immigrants and research has shown that second-generation Southeast Asian immigrants in France deviate from the fertility patterns of their parents, withfirst birth rates even lower than native French women (Pailhé 2017).

\section{Conclusion}

Our results show the development of mixed gender preferences alongside a weak (non-significant) daughter preference for offspring among native French women, and an overall deviation from the gender preferences prevailing in the country of origin for North African, Turkish, Sub-Saharan African and Vietnamese-Laos-Cambodian immigrant women in France. Second generation North African immigrant women display a decline in son preference when transitioning to the second parity and the emergence of a weak daughter preference when transitioning to the third parity. Gender preferences of second-generation Turkish immigrant women evolve into a preference for a gender mix of children when transitioning to the third parity. Second generation Sub-Saharan African display a daughter preference when transitioning to the third parity. Second generation Vietnamese-Laos-Cambodian immigrant women display a daughter preference at the third parity.

The evolutionary nature of gender preferences for offspring across subsequent cohorts of native French women suggests that the French pattern is similar to its German and, in particular, Swedish counterparts. The latter countries have displayed weak daughter preference and persistent daughter preference strengthening over decades, respectively (Carol/Hank 2020; Ezdi/Baş 2020; Miranda et al. 2018). For France, this suggests that modernisation, changes in the societal gender system, 
female labour force participation and work-family reconciliatory/pro-birth policies may lead to the emergence of a strong daughter preference at least at the third parity among younger/future cohorts of French women (Pollard/Morgan 2002; Toulemon et al. 2008; Miranda et al. 2018). It would therefore be fruitful to investigate gender preferences for offspring among younger French women on a periodic basis using recent datasets as they are released.

Despite the fertility decline observed across subsequent generations of all immigrant groups investigated, overall, we do not suspect the gender preferences displayed by North African, Turkish, Vietnamese-Laos-Cambodian and Sub-Saharan African immigrants to be a consequence of the constraint caused by this decline. Such a constraint, resulting from the inverse relationship between fertility and expression of gender preferences, would strengthen country of origin gender preferences and thus enhance son preference among North African and Turkish immigrants. This is exhibited by Indian and Pakistani immigrants in the United Kingdom, for example, who experience a contraction in fertility compared with their counterparts in their country of origin and a stronger expression of son preference, i.e. at lower birth parities compared with their counterparts in their respective countries of origin (Dubuc/Coleman 2007; Adamou et al. 2013). Rather, our results show a weakening of these preferences among Turkish and North African immigrants and possibly Vietnamese-Lao-Cambodian immigrants, and altered preferences (i.e. daughter preference) among Sub-Saharan African immigrants. This may be the consequence of the selection hypothesis (especially in the case of North African immigrants), the adaptation hypothesis or a combination of the two. The viable application of these hypotheses has already been established in the context of immigrant gender preferences. For example, Indian immigrant women in Norway, and Indian, Chinese and South Korean immigrant women in Sweden who had been residing in the respective countries for an extended period of time, exhibited a decline in son preference (via a decrease in masculinised sex ratios at birth) in the period 20002015 (Tønnessen et al. 2013; Mussino et al. 2018).

The malleable nature of North African, Sub-Saharan African and potentially Vietnamese-Laos-Cambodian immigrants' gender preferences as well as the decline in fertility also portray the dual influence of French mainstream society and the respective immigrant group's minority subculture in reformulating the immigrants' fertility and gender preferences. While French mainstream culture may have steered immigrants away from their native country gender preferences, the influence of the minority subculture may have led to the development of new preferences to specifically meet the demands of the immigrant subgroups in France. The viability of this explanation remains high in France where welfare state policies have reduced differences among population subgroups, the size of the main minority groups remains large, and residential and school segregation is substantial (Kulu et al. 2017).

We caution our readers to interpret our results while taking note of regional clustering of immigrant's countries of origin. With the exception of native French women and Turkish immigrant women, our analyses cluster countries together at the regional level. Such regional aggregation may hide important country-level 
differences both with regard to gender preferences and the ability of immigrants to integrate. For example, in this paper, the interpretation of gender preferences for Vietnam-Laos-Cambodia presents some difficulties because of contrasting gender preferences in Vietnam and Cambodia, i.e. son preference in Vietnam (Guilmoto 2009) and daughter preference in Cambodia (Fuse 2010). This is a problem that other authors have also faced (e.g. Mussino et al. 2018) when interpreting gender neutral preferences for Southeast Asian immigrants in Sweden. However, we note that many studies on fertility and gender preferences, especially for France using the same datasets, have used regional classifications similar to ours to obtain empirically and theoretically sound results. We therefore find our regional clustering and the subsequent results to be theoretically and empirically sound and are confident in their ability to serve as indicators of the immigrant integration process.

We conclude that our results for gender preferences among natives and immigrants in France provide evidence of the cultural adaptation of immigrants in France whilst also displaying elements of immigrant selectivity and the influence of a minority subculture. The fact that clear preferences for a gender mix or daughters only become evident in the second generation shows that early socialisation is important in the formulation of gender preferences for offspring. The development of a daughter preference among second-generation North African (weak), SubSaharan African and Vietnam-Laos-Cambodian women shows the role of minority subculture alongside cultural adaptation as, to date, among French women there is non-significant evidence of daughter preference. This shows that the modernisation and work-family reconciliatory policies that are leading to the evoution of gender preferences for offspring among native French women may also be influencing immigrant women's gender preferences for offspring. Our results suggest that this would indicate the integration of immigrants on multiple fronts as we confirm that these gender preferences for offspring emerge alongside a decline in immigrant fertility rates across subsequent generations. As we expect daughter preference in France to become more prominent in the forthcoming decades, we would expect immigrant gender preferences for offspring to converge more closely with those of the native French population. Future research should therefore continue to use more recent data to see whether/how gender preferences have evolved and continue to evolve in the country among natives and immigrants, and if possible examine gender preferences by country or origin rather than region of origin.

\section{References}

Abrevaya, Jason 2009: Are There Missing Girls in the United States? Evidence from Birth Data. In: American Economic Journal: Applied Economics 1,2: 1-34. https://doi.org/10.1257/app.1.2.1

Adamou, Adamos; Drakos, Christina; lyer, Sriya 2013: Missing women in the United Kingdom. In: IZA Journal of Migration 2,10. https://doi.org/10.1186/2193-9039-2-10 
Afulani, Patience A.; Asunka, Joseph 2015: Socialization, Adaptation, Transnationalism, and the Reproductive Behavior of Sub-Saharan African Migrants in France.In: Population Research and Policy Review 34,4: 561-592. https://doi.org/10.1007/s11113-015-9360-2

Algan, Yann; Bisin, Alberto; Verdier, Thierry, C. 2012: Introduction: Perspectives on Cultural Integration of Immigrants. In: Algan, Yann et al. (Eds.): Cultural Integration of Immigrants in Europe. Oxford University Press: 1-48.

https://doi.org/10.1093/acprof:oso/9780199660094.003.0001

Algan, Yann; Landais, Camilla; Senik, Claudia 2012: Cultural Integration in France. In: Yann Algan et al. (Eds.): Cultural Integration of Immigrants in Europe. Oxford University Press: 49-68. https://doi.org/10.1093/acprof:oso/9780199660094.003.0002

Almond, Douglas; Edlund, Lena; Milligan, Kevin 2013: Son Preference and the Persistence of Culture: Evidence from South and East Asian Immigrants to Canada. In: Population and Development Review 39,1: 75-95. https://doi.org/10.1111/j.1728-4457.2013.00574.x

Altindag, Onur 2016: Son Preference, Fertility Decline, and the Nonmissing Girls of Turkey. In: Demography 53,2: 541-566. https://doi.org/10.1007/s13524-016-0455-0

Ambrosetti, Elena et al. 2015: Sex imbalances at birth in migratory context. In: Genus 71,2-3: 29-51.

Andersson, Gunnar et al. 2006: Gendering Family Composition: Sex Preferences for Children and Childbearing Behavior in the Nordic Countries. In: Demography 43,2: 255-267. https://doi.org/10.1353/dem.2006.0010

Arnold, Fred 1997: Gender Preferences for Children. DHS Comparative Studies No. 23. Calverton, Marylan: Macro International Inc.

Arnold, Fred; Kuo, Eddie C. Y. 1984: The Value of Daughters and sons: A comparative Study of the Gender Preferences of Parents. In: Journal of Comparative Family Studies 15,2: 299-318. https://doi.org/10.3138/jcfs.15.2.299

Baykara-Krumme, Helen; Milewski, Nadja 2017: Fertility Patterns Among Turkish Women in Turkey and Abroad: The Effects of International Mobility, Migrant Generation, and Family Background. In: European Journal of Population 33,3: 409-436. https://doi.org/10.1007/s10680-017-9413-9

Calendrier des enquêtes auprès des particuliers pour 2020 et 2021: Insee (2020, November). Institut National d'études Démographiques [https://www.insee.fr/, 01.12.2020]

Carol, Sarah; Hank, Karsten 2020: Natives' and Immigrants' Gender Preferences for Children in Germany. In: European Journal of Population 36,2: 235-246. https://doi.org/10.1007/s10680-019-09527-y

Dahl, Edgar et al. 2003: Preconception sex selection for non-medical reasons: a representative survey from Germany. In: Human Reproduction 18,10: 2231-2234. https://doi.org/10.1093/humrep/deg426

Desplanques, Guy 1987: Cycle de vie et milieu social. In: Collections de I'INSEE. Série D. Démographie et emploi 117.

Dubuc, Sylvie; Coleman, David 2007: An Increase in the Sex Ratio of Births to India-born Mothers in England and Wales: Evidence for Sex-Selective Abortion. In: Population and Development Review 33,2. 383-400. https://doi.org/10.1111/j.1728-4457.2007.00173.x 
Dupray, Arnaud; Pailhé, Ariane 2018: Does employment uncertainty particularly impact fertility of children of North African immigrants in France? A gender perspective. In: Journal of Ethnic and Migration Studies 44,3: 401-424. https://doi.org/10.1080/1369183X.2017.1313107

Duthé, Géraldine et al. 2012: High sex ratios at birth in the Caucasus: Modern technology to satisfy old desires. In: Population and Development Review 38,3: 487-501. https://doi.org/10.1111/j.1728-4457.2012.00513.x

EFL: Enquête Famille et logements / CASD. (n.d.). Centre d'accès Sécurisé Aux Données [https://www.casd.eu/, 01.12.2020].

Ezdi, Sehar; Baş, Ahmet M. 2020: Gender preferences and fertility: Investigating the case of Turkish immigrants in Germany. In: Demographic Research 43, 59-96. https://doi.org/10.4054/DemRes.2020.43.3

Famille et logements 2011: INSEE [producers], ADISP [distributor].

Fuse, Kana 2010: Variations in attitudinal gender preferences for children across 50 lessdeveloped countries. In: Demographic Research 23: 1031-1048. https://doi.org/10.4054/DemRes.2010.23.36

Gill, Aisha; Mitra-Kahn, Trishima 2009: Explaining Daughter Devaluation and the Issue of Missing Women in South Asia and the UK. In: Current Sociology 57,5: 684-703. https://doi.org/10.1177/0011392109337652

Gonzalez, Libertad 2014: Missing girls in Spain. Economics Working Paper. Working Paper. Department of Economics and Business. Universitat Pompeu Fabra [https:// EconPapers.repec.org/RePEc:upf:upfgen:1420, 16.02.2020].

Gray, Edith; Evans, Ann 2005: Parity Progression in Australia: What Role Does Sex of Existing Children Play? In: The Australian Journal of Social Issues 40,4: 505-520.

Guilmoto, Christophe Z. 2009: The Sex Ratio Transition in Asia. In: Population and Development Review 35,3: 519-549. https://doi.org/10.1111/j.1728-4457.2009.00295.x

Hank, Karsten 2007: Parental Gender Preferences and Reproductive Behaviour: A Review of the Recent Literature. In: Journal of Biosocial Science 39,5: 759-767. https://doi.org/10.1017/S0021932006001787

Hank, Karsten; Kohler, Hans-Peter 2000: Gender Preferences for Children in Europe: Empirical Results from 17 FFS Countries. In: Demographic Research 2,1. https://doi.org/10.4054/DemRes.2000.2.1

Hank, Karsten; Kohler, Hans-Peter 2003: Sex Preferences for Children Revisited: New Evidence from Germany. In: Population (English Edition) 58,1: 131. https://doi.org/10.2307/3246647

INED 2020: Enquête “Trajectoires et Origines" 1. Institut national d'études démographiques [https://teo1.site.ined.fr/, 01.12.2020].

INSEE 2020: Enquête sur la famille et les logements. Institut National de la Statistique et des études économiques [https://www.insee.fr/, 01.12.2020].

Jacobsen, Rune; Møller, Henrik; Engholm, Gerda 1999: Fertility rates in Denmark in relation to the sexes of preceding children in the family. In: Human Reproduction 14,4: 1127-1130. https://doi.org/10.1093/humrep/14.4.1127

Jiang, Quanbao; Li, Ying, Sánchez-Barricarte, Jesús J. 2016: Fertility Intention, Son Preference, and Second Childbirth: Survey Findings from Shaanxi Province of China. In: Social Indicators Research 125,3: 935-953. https://doi.org/10.1007/s11205-015-0875-z 
Kulu, Hill et al. 2017: Fertility by Birth Order among the Descendants of Immigrants in Selected European Countries: Fertility by Birth Order Among Descendants of Immigrants. In: Population and Development Review 43,1: 31-60. https://doi.org/10.1111/padr.12037

Kulu, Hill; González-Ferrer, Amparo 2014: Family Dynamics Among Immigrants and Their Descendants in Europe: Current Research and Opportunities. In: European Journal of Population 30,4: 411-435. https://doi.org/10.1007/s10680-014-9322-0

Lillehagen, Mats; Lyngstad, Torkild H. 2018: Immigrant mothers' preferences for children's sexes: A register-based study of fertility behaviour in Norway. In: Population Studies 72,1: 91-107. https://doi.org/10.1080/00324728.2017.1421254

McDougall, Janette; Dewit, David J.; Ebanks, G. Edward 1999: Parental Preferences for Sex of Children in Canada. In: Sex Roles 41,7/8: 615-626. https://doi.org/10.1023/A:1018803723262

Mills, Melinda; Begall, Katia 2010: Preferences for the sex-composition of children in Europe: A multilevel examination of its effect on progression to a third child. In: Population Studies 64,1: 77-95. https://doi.org/10.1080/00324720903497081

Miranda, Vitor; Dahlberg, Johan; Andersson, Gunnar 2018: Parents' Preferences for Sex of Children in Sweden: Attitudes and Outcomes. In: Population Research and Policy Review 37,3: 443-459. https://doi.org/10.1007/s11113-018-9462-8

Mussino, Eleonora; Miranda, Vitor; Ma, Li 2018: Changes in sex ratio at birth among immigrant groups in Sweden. In: Genus 74,13. https://doi.org/10.1186/s41118-018-0036-8

Mussino, Eleonora; Miranda, Vitor; Ma, Li 2019: Transition to third birth among immigrant mothers in Sweden: Does having two daughters accelerate the process? In: Journal of Population Research 36,2: 81-109. https://doi.org/10.1007/s12546-019-09224-x

Pailhé, Ariane 2017: The convergence of second-generation immigrants' fertility patterns in France: The role of sociocultural distance between parents' and host country. In: Demographic Research 36,45 1361-1398. https://doi.org/10.4054/DemRes.2017.36.45

Penn, Roger; Lambert, Paul 2002: Attitudes towards ideal family size of different ethnic/ nationality groups in Great Britain, France and Germany. In: Population Trends 108: 49-58.

Pison, Gilles 2004: Fewer births, but a boy at all costs: Selective female abortion in Asia. In: Population \& Societies 404. Institut National d'Etudes Demographiques: 1-4.

Pison, Gilles 2019: The number and proportion of immigrants in the population: International Comparisons. In: Population \& Societies 563. Institut National d'Etudes Demographiques: 1-4.

Pison, Gilles 2020: France has the highest fertility in Europe. In: Population \& Societies 575. Institut National d'Etudes Demographiques: 1-4.

Pollard, Michael S.; Morgan, S. Philip 2002: Emerging Parental Gender Indifference? Sex Composition of Children and the Third Birth. In: American Sociological Review 67,4: 600-613. https://doi.org/10.2307/3088947

Rossi, Pauline; Rouanet, Léa 2015: Gender Preferences in Africa: A Comparative Analysis of Fertility Choices. In: World Development 72: 326-345. https://doi.org/10.1016/j.worlddev.2015.03.010

Saarela, Jan; Finnäs, Fjalar 2014: Sex composition of children, parental separation, and parity progression: Is Finland a Nordic outlier? In: Demographic Research 30,2: 49-70. https://doi.org/10.4054/DemRes.2014.30.2 
Singer, Judith D.; Willett, John B. 1993: It's About Time: Using Discrete-Time Survival Analysis to Study Duration and the Timing of Events. In: Journal of Educational Statistics 18,2: 155-195. https://doi.org/10.3102/10769986018002155

Singh, Narpinder et al. 2010: Different sex ratios of children born to Indian and Pakistani immigrants in Norway. In: BMC Pregnancy and Childbirth 10,40. https://doi.org/10.1186/1471-2393-10-40

Tian, Felicia F.; Morgan, S. Philip 2015: Gender Composition of Children and the Third Birth in the United States: Gender Composition of Children and the Third Birth. In: Journal of Marriage and Family 77,5: 1157-1165. https://doi.org/10.1111/jomf.12218

Tønnessen, Marianne; Aalandslid, Vebjørn; Skjerpen, Terje 2013: Changing trend? Sex ratios of children born to Indian immigrants in Norway revisited. In: BMC Pregnancy and Childbirth 13,1. https://doi.org/10.1186/1471-2393-13-170

Toulemon, Laurent 2004: Fertility among immigrant women: New data, a new approach: In: Population \& Societies 400. L'Institut National d'Etudes Demographiques: 1-4.

Toulemon, Laurent; Pailhé, Ariane; Rossier, Clémentine 2008: France: High and stable fertility. In: Demographic Research 19: 503-556. https://doi.org/10.4054/DemRes.2008.19.16

Trajectoires et origines (TeO) - version reduite - 2008: INSEE, INED [producers], ADISP [distributor].

Verropoulou, Georgia; Tsimbos, Cleon 2010: Differentials in Sex Ratio at Birth among Natives and Immigrants in Greece: An Analysis Employing Nationwide Micro-data. In: Journal of Biosocial Science 42,3: 425-430. https://doi.org/10.1017/S0021932009990599

Volant, Sabrina; Pison, Gilles; Héran, François 2019: French fertility is the highest in Europe. Because of its immigrants? In: Population \& Societies 568. Institut National d'Etudes Demographiques: 1-4.

Dr. Sehar Ezdi $(\varangle)$. CERPOP, Université de Toulouse, Inserm, UPS. Toulouse, France.

E-mail: sehar.ezdi@inserm.fr, seharezdi@gmail.com

Dr. Sabrina Pastorelli. Centre National de la Recherche Scientifique (CNRS), Centre

Maurice Halbwachs (CNRS/EHESS/ENS). Paris, France.

E-mail: pastorelli.sabrina@gmail.com

URL: https://cnrs.academia.edu/SabrinaPastorelli 


\section{Comparative Population Studies}

WWW.comparativepopulationstudies.de

ISSN: 1869-8980 (Print) - 1869-8999 (Internet)

\section{Published by}

Prof. Dr. Norbert F. Schneider

Federal Institute for Population Research D-65180 Wiesbaden / Germany

\section{(c) BY-SA}

2021

\section{Managing Editor}

Prof. Dr. Johannes Huinink

Dr. Katrin Schiefer

\section{Editorial Assistant}

Beatriz Feiler-Fuchs

Wiebke Hamann

\section{Layout}

Beatriz Feiler-Fuchs

E-mail:cpos@bib.bund.de

\section{Scientific Advisory Board}

Karsten Hank (Cologne)

Michaela Kreyenfeld (Berlin)

Marc Luy (Vienna)

Natalie Nitsche (Rostock)

Zsolt Spéder (Budapest)

Rainer Wehrhahn (Kiel)

\section{Board of Reviewers}

Bruno Arpino (Barcelona)

Kieron Barclay (Rostock)

Laura Bernardi (Lausanne)

Gabriele Doblhammer (Rostock)

Anette Eva Fasang (Berlin)

Michael Feldhaus (Oldenburg)

Tomas Frejka (Sanibel)

Alexia Fürnkranz-Prskawetz (Vienna)

Birgit Glorius (Chemnitz)

Fanny Janssen (Groningen)

Frank Kalter (Mannheim)

Stefanie Kley (Hamburg)

Bernhard Köppen (Koblenz)

Anne-Kristin Kuhnt (Duisburg)

Hill Kulu (St Andrews)

Nadja Milewski (Wiesbaden)

Roland Rau (Rostock)

Thorsten Schneider (Leipzig)

Tomas Sobotka (Vienna)

Jeroen J. A. Spijker (Barcelona)

Heike Trappe (Rostock)

Helga de Valk (The Hague)

Sergi Vidal (Barcelona)

Michael Wagner (Cologne) 